\title{
TuberOus SClerosis registry to increase disease Awareness (TOSCA) - baseline data on 2093 patients
}

\author{
John C. Kingswood ${ }^{1 *}$, Guillaume B. d'Augères ${ }^{2}$, Elena Belousova ${ }^{3}$, José C. Ferreira ${ }^{4}$, Tom Carter ${ }^{5}$, Ramon Castellana ${ }^{6}$, \\ Vincent Cottin ${ }^{7}$, Paolo Curatolo ${ }^{8}$, Maria Dahlin ${ }^{9}$, Petrus J. de Vries ${ }^{10}$, Martha Feucht ${ }^{11}$, Carla Fladrowski ${ }^{12,13}$, \\ Gabriella Gislimberti ${ }^{14}$, Christoph Hertzberg ${ }^{15}$, Sergiusz Jozwiak ${ }^{16}$, John A. Lawson ${ }^{17}$, Alfons Macaya ${ }^{18}$, \\ Rima Nabbout ${ }^{19}$, Finbar O'Callaghan ${ }^{20}$, Mirjana P. Benedik ${ }^{21}$, Jiong Qin ${ }^{22}$, Ruben Marques ${ }^{14}$, Valentin Sander ${ }^{23}$, \\ Matthias Sauter ${ }^{24}$, Yukitoshi Takahashi ${ }^{25}$, Renaud Touraine ${ }^{26}$, Sotiris Youroukos ${ }^{27}$, Bernard Zonnenberg ${ }^{28}$, \\ and Anna C. Jansen ${ }^{29}$ on behalf of TOSCA consortium and TOSCA investigators
}

\begin{abstract}
Background: Tuberous sclerosis complex (TSC) is a rare autosomal dominant genetic disorder. Many gaps remain in the understanding of TSC because of the complexity in clinical presentation. The TuberOus SClerosis registry to increase disease Awareness (TOSCA) is an international disease registry designed to address knowledge gaps in the natural history and management of TSC. Here, we present the baseline data of TOSCA cohort.
\end{abstract}

Methods: Patients of any age diagnosed with TSC, having a documented visit for TSC within the preceding 12 months, or newly diagnosed individuals were included. The registry includes a "core" section designed to record detailed background information on each patient including disease manifestations, interventions, and outcomes collected at baseline and updated annually. "Subsections" of the registry recorded additional data related to specific features of TSC.

Results: Baseline "core" data from 2093 patients enrolled from 170 sites across 31 countries were available at the cut-off date September 30, 2014. Median age of patients at enrollment was 13 years (range, 0-71) and at diagnosis of TSC was 1 year (range, 0-69). The occurrence rates of major manifestations of TSC included - cortical tubers (82.2\%), subependymal nodules (78.2\%), subependymal giant cell astrocytomas (24.4\%), renal angiomyolipomas (47.2\%), lymphangioleiomyomatosis (6.9\%), cardiac rhabdomyomas (34.3\%), facial angiofibromas (57.3\%), forehead plaque (14.1\%), $\geq 3$ hypomelanotic macules (66.8\%), and shagreen patches (27.4\%). Epilepsy was reported in 1748 (83.5\%) patients, of which 1372 were diagnosed at $\leq 2$ years (78\%). Intellectual disability was identified in 451 (54.9\%) patients of those assessed. TSC-associated neuropsychiatric disorders (TAND) were diagnosed late, and not evaluated in 30-50\% of patients.

Conclusion: TOSCA is the largest clinical case series of TSC to date. It provided a detailed description of the disease trajectory with increased awareness of various TSC manifestations. The rates of different features of TSC reported here reflect the age range and referral patterns of clinics contributing patients to the cohort. Documentation of TAND and LAM was poor. A widespread adoption of the international TSC assessment and treatment guidelines, including use of the TAND Checklist, could improve surveillance. The registry provides valuable insights into the necessity for monitoring, timing, and indications for the treatment of TSC.

Keywords: Tuberous sclerosis, Registry, Epilepsy, Subependymal giant cell astrocytoma, Angiomyolipoma, TOSCA

\footnotetext{
* Correspondence: chris.kingswood@bsuh.nhs.uk

'Sussex Kidney Unit, Royal Sussex County Hospital, Eastern Road, Brighton BN2 5BE, UK

Full list of author information is available at the end of the article
} International License (http://creativecommons.org/licenses/by/4.0/), which permits unrestricted use, distribution, and reproduction in any medium, provided you give appropriate credit to the original author(s) and the source, provide a link to the Creative Commons license, and indicate if changes were made. The Creative Commons Public Domain Dedication waiver (http://creativecommons.org/publicdomain/zero/1.0/) applies to the data made available in this article, unless otherwise stated. 


\section{Background}

Tuberous sclerosis complex (TSC) is a rare genetic disorder characterized by the development of benign tumors in several organs of the body [1]. The birth incidence of the disorder is approximately 1 in 5800 individuals [2]. TSC is caused by genetic mutations in either of the TSC1 or TSC2 genes [3]. Based on routine diagnostic techniques, a pathogenic mutation is detected in up to 85-90\% of individuals with a clinical diagnosis of TSC [1]. In the remaining $10-15 \%$ patients with 'no mutation identified', next generation DNA sequencing (NGS), a high-throughput sequencing, identified mosaic or intronic mutations in TSC1 or TSC 2 genes in a vast majority suggesting that it is unlikely that a third TSC gene exists [4]. Mutations of TSC1 or TSC2 gene result in overactivation of the mammalian target of rapamycin (mTOR) complex 1 , a key intracellular regulator of cell growth and proliferation, resulting in the hamartomatous lesions found in multiple organs $[5,6]$. Recent research has helped us understand the pathophysiology of TSC, which has led to the use of mTOR inhibitors for the treatment of certain manifestations of TSC including subependymal giant cell astrocytomas (SEGAs) and renal angiomyolipomas [7-10]. The recently revised guidelines for the surveillance and management of TSC provided updated recommendations for standard, optimal care for patients [10].

There is, however, still a lack of clarity with respect to the natural history of many of the TSC manifestations, their variability, the age-related expression pattern, and their prognostic roles. Gaps also exist in understanding the rare symptoms and comorbidities of TSC, the relationship between genotype and phenotype, and the various interventions, treatments, and their outcomes. An improved understanding of the natural history of TSC is essential in order to evaluate the benefitrisk ratio of any intervention accurately. TuberOus SClerosis registry to increase disease Awareness (TOSCA) was established as a multicenter, international disease registry with the specific aim to gather clinical data on this rare disease in a systematic and longitudinal way. TOSCA consists of a "core" dataset representing the diagnostic characteristics and core associated clinical features, and "petal projects" which represent detailed sub-projects focusing on specific TSC manifestations. The results from the baseline core data of the TOSCA cohort are reported here.

\section{Methods}

The study methods have been described in detail previously [11]. All patients gave informed consent. TOSCA is a multicenter, international disease registry that was designed to collect data on patients with TSC from many countries worldwide. Patients of any age with a diagnosis of TSC (definite, probable, or possible) and with a documented clinical visit for TSC within the past
12 months or newly diagnosed with TSC were eligible. The certainty of diagnosis was based on the 1998 revised Gomez criteria.[12] The registry consists of a "core" section and subsections or "petals". The "core" section collected general information on patients' background which included demographic data, family history, prenatal history, and disease features such as neurological and neuropsychiatric, renal, cardiovascular, pulmonary, dermatological, and others. This information was collected at baseline and is being updated annually. Subsections ("petals") are being developed as research projects to record in-depth data related to specific disease manifestations. Pediatric and adult sites with specialists in managing one or more aspects of TSC were included in the registry. Patients will be followed up for up to five years and an interim analysis will be conducted every year.

\section{Results}

\section{Overall findings}

TOSCA recruited a total of 2223 patients from 170 centers in 31 countries (Fig. 1), over half of them (57\%) from neuropediatric/pediatric clinics (Fig. 2). At the cutoff date September 30, 2014, complete baseline data from 2093 patients (1009 male and 1084 female) were available. Median age at inclusion in TOSCA was 13 years (range, $0-71$ ). Patient distribution by age at inclusion in TOSCA is shown in Fig. 3 ( $\leq 18$ years, 63.3\%; $>18$ years, $36.7 \%$ ). Median age at diagnosis of TSC was 1 year (range 0-69). TSC was diagnosed prenatally in 124 (5.9\%) patients. Molecular testing had been performed in 902 (43.1\%) patients. TSC1 mutations were identified in $19.7 \%$ of the patients and TSC2 in $63.3 \%$ (Table 1). Only known pathogenic mutations as defined in the Leiden Open Variation Database (LOVD) were counted.[13] Five patients had both TSC1 and TSC2 mutations.

\section{Neurological manifestations}

Cortical tubers and subependymal nodules were the most commonly reported neurological manifestations (reported in 82.2 and $78.2 \%$ of patients, respectively). A total of $510(24.4 \%)$ patients had ever been diagnosed with SEGA (Table 2). For TOSCA, a broad definition of SEGA was adopted, based on the presence of a lesion near the foramen of Monro without specific criteria for size or growth. Median age at SEGA diagnosis was 8 years (range $0-51$ ) (Additional file 1). SEGA was diagnosed before age 2 years in 132 (26.4\%), before age 18 years in 278 (55.6\%), and after age 18 years in 90 (18\%) patients. SEGA was present at the time of recruitment in TOSCA in $422(82.7 \%)$ patients. Of these, 195 (46.2\%) were bilateral and 155 (36.7\%) showed growth since the previous scan. Growth was reported in 10 out 


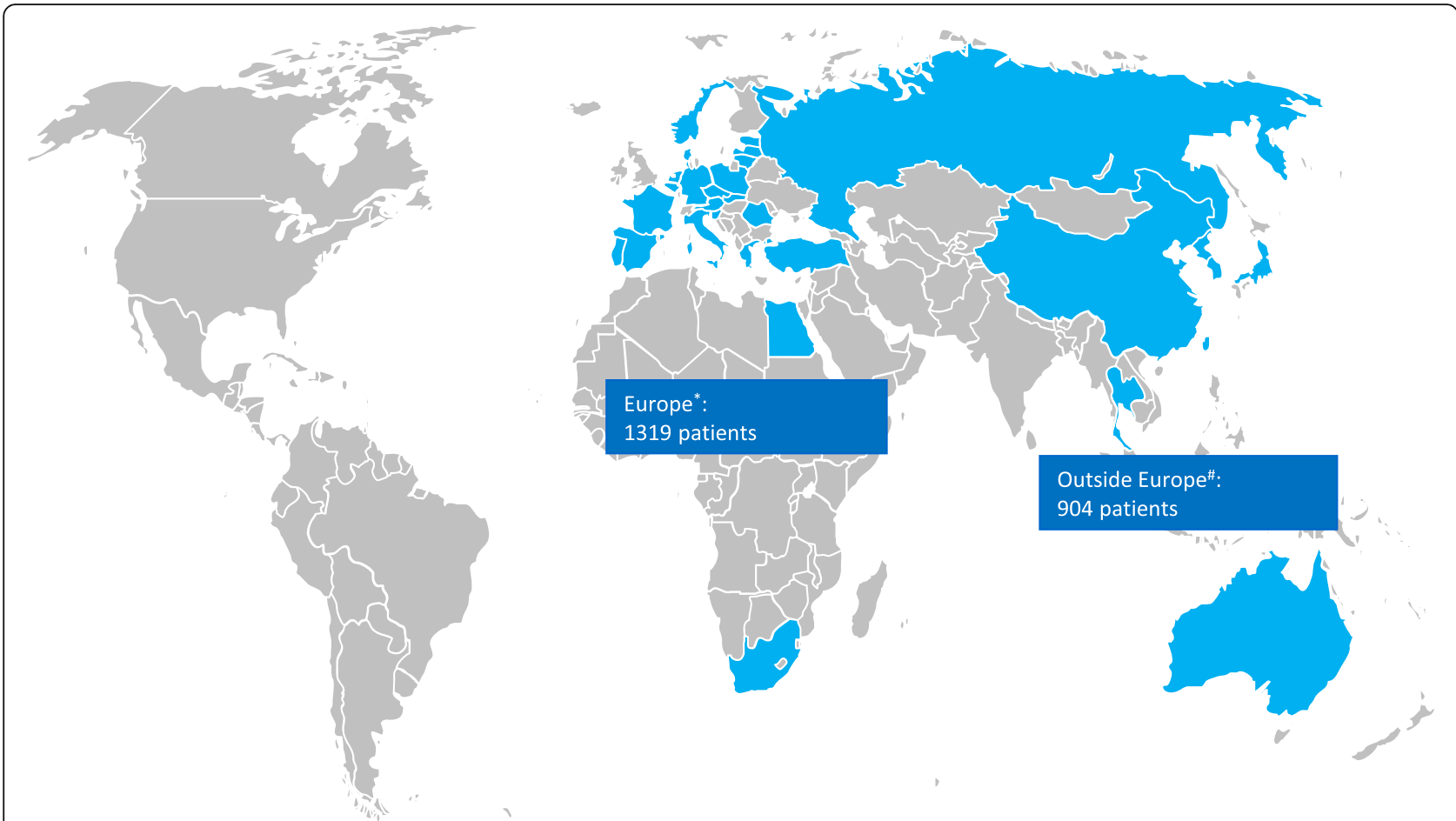

Fig. 1 Patients enrolled from different countries in TOSCA ( $N=2223)$. ${ }^{*}$ European countries include: Austria, Belgium, Czech Republic, Denmark, Estonia, France, Germany, Greece, Italy, Latvia, Lithunia, Netherlands, Norway, Poland, Portugal, Romonia, Slovakia, Slovenia, Spain, and Sweden. \#Outside Europe include: Australia, Israel, Japan, Korea, Russia, South Africa, Mainland China, Hongkong, Macau, Taiwan, Thailand, and Turkey

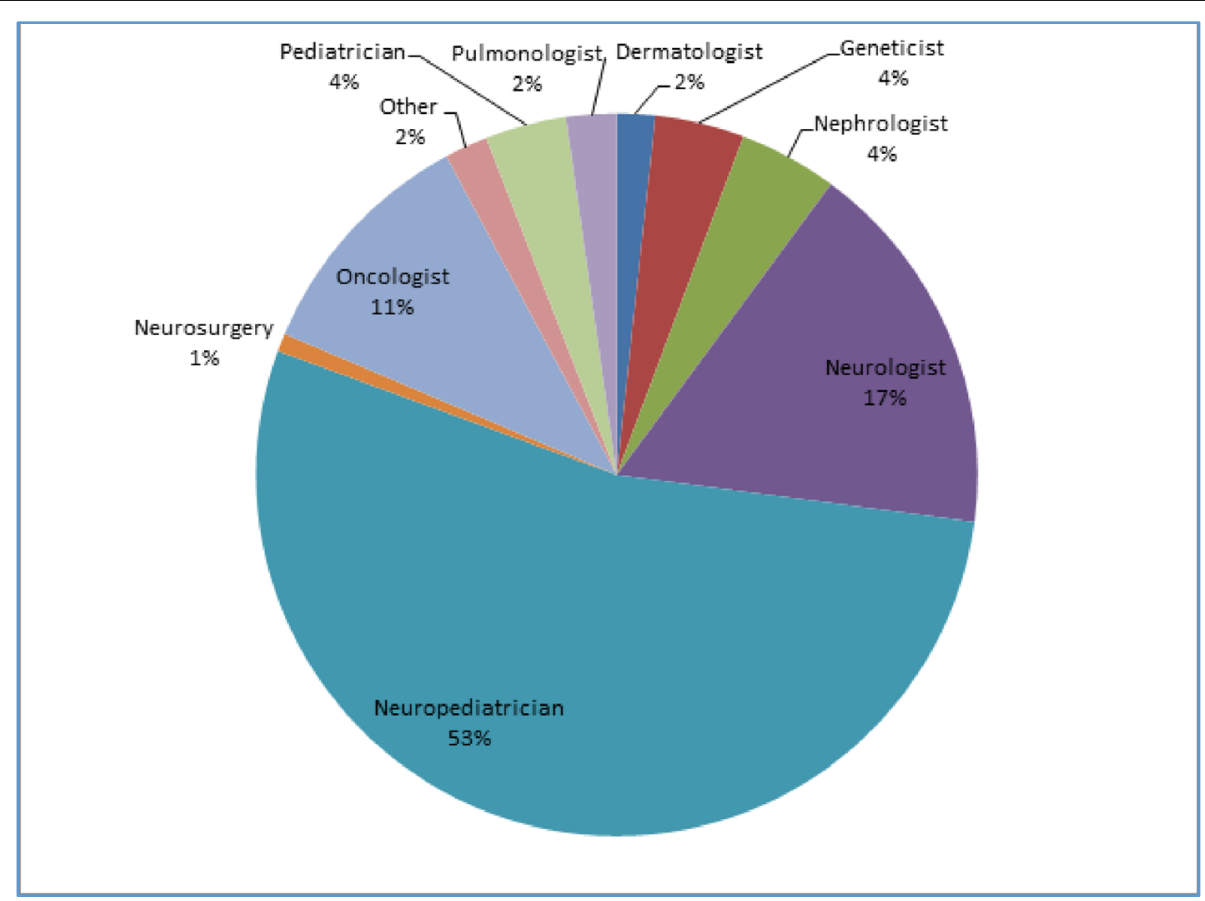

Fig. 2 Distribution of TOSCA participants among different specialties $(N=2223)$ 


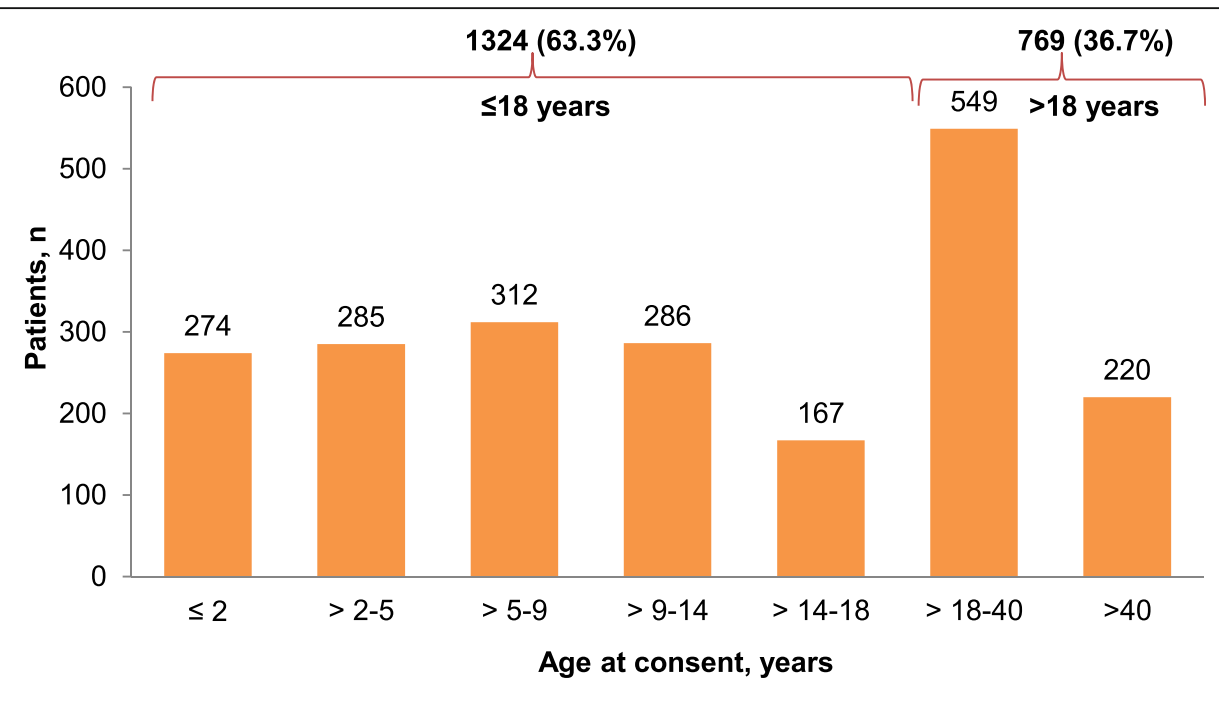

Median age at consent was 13 years (range, $0-71$ ).

Fig. 3 Patient distribution by age for inclusion in TOSCA ( $N=2093)$. Median age at consent was 13 years (range $0-71$ )

of 93 patients with SEGA diagnosed after age 18 years. The median time between scans was 1 year (range 0-22).

In 207 out of the 510 patients with SEGA, a pathogenic mutation was detected in TSC1 in 22 patients and TSC2 in 185 patients. SEGA were bilateral in 18\% and growing in $4.5 \%$ of patients with mutations in TSC1 versus in 34 and $16 \%$ of patients with mutations in TSC2. The majority (70.9\%) of the patients with SEGA were asymptomatic at the time of assessment. In symptomatic patients, the most common symptoms/signs were increase in seizure frequency (65 [15.4\%]), behavioral disturbances (50 [11.8\%]), headache (34 [8.1\%]), and regression or loss of cognitive skills (31 [7.3]). A total of 189 (9\%) patients received treatment before baseline visit. Median time from SEGA diagnosis to treatment was less than 1 year (range $0-15)$. The most common treatment modality was surgery (114 [60.3\%]), mTOR inhibitor (88 [46.6\%]), and ventriculoperitoneal shunt (21 [11.1\%]), provided as monotherapy or in combination with other treatments.

Epilepsy was reported in 1748 (83.5\%) patients (Table 2). The most common seizure type was focal seizures (1169 [66.9\%]). The median age at diagnosis of focal seizures was 1 year. Most of the patients (73\%) were diagnosed at or before the age of 2 years. Of the 1144 patients who received treatment, 745 (65.1\%) were treated with gamma-aminobutyric acid (GABAergics [as a single agent or in combination with another treatment modality]). Additional treatment modalities as single agents or in combination with other treatment modalities included mTOR inhibitor (80 [7.0\%]), surgery (80 [7.0\%]), ketogenic diet (49 [4.3\%]), vagal nerve stimulation (45 [3.9\%]), fructose derivatives (33 [2.9\%]), and adrenocorticotropic hormone (ACTH, 31 [2.7\%]). Focal seizures were controlled by treatment in $672(58.7 \%)$ patients, while not controlled in 411 (35.9\%) patients. The next most common seizure type reported was infantile spasms (679 [38.8\%]). Of the 660 patients who received treatment for infantile spasms, 517 (78.3\%) were treated with GABAergics and $118(17.9 \%)$ with $\mathrm{ACTH}$, either as monotherapy or in combination with other therapies. Infantile spasms were controlled by treatment in $471(71.5 \%)$ patients, while not controlled in 105 (15.9\%) patients.

\section{TSC-associated neuropsychiatric disorders (TAND)}

Among the patients who were evaluated for TAND, academic/scholastic difficulties were noted in 682 $(57.8 \%)$ patients. Of the $822(39.2 \%)$ patients who had been evaluated using intelligent quotient (IQ)-type tests, 451 (54.9\%) patients had mild to profound intellectual disability. Autism spectrum disorder (ASD), attention deficit hyperactivity disorder (ADHD), anxiety disorder, and depressive disorder were reported in 20.7, 19.6, 9.1, and $6.1 \%$ of patients excluding patients whose data was not available. The mean (median [range]) age at diagnosis of neuropsychiatric disorders were - ASD, 7.6 (5 [0-38]); ADHD, 7.7 (6 [0-38]); anxiety, 17.8 (15 [0-50]); depression, 24.4 (21 [3-49]) years (Additional file 1). Neuropsychological skills were assessed in 510 patients of whom $281(55 \%)$ patients had performance $<5^{\text {th }}$ percentile. Patients who reported at least one behavioral problem were 745 (35.6\%). Behavioral problems reported in $>10 \%$ patients were sleep difficulties, impulsivity-overactivity, severe aggression, anxiety, and mood swings. Missing data of TAND features in the TOSCA population was high (Table 3). 
Table 1 Baseline patient demographics and clinical characteristics ( $N=2093)$

\begin{tabular}{|c|c|}
\hline Characteristics & Baseline data \\
\hline Age at diagnosis of TSC, years, median (range) & $1.0(0-69)$ \\
\hline \multicolumn{2}{|l|}{ Gender, n (\%) } \\
\hline Male & $1009(48.2)$ \\
\hline Female & $1084(51.8)$ \\
\hline Patients with molecular testing, $\mathrm{n}(\%)$ & $902(43.1)$ \\
\hline Genetic testing ${ }^{\mathrm{b}}, \mathrm{n}\left(\%^{\mathrm{c}}\right)$ & $885(98.1)$ \\
\hline No mutation identified & $125(13.9)$ \\
\hline TSC1 mutation & $178(19.7)$ \\
\hline TSC2 mutation & $571(63.3)$ \\
\hline \multicolumn{2}{|l|}{ Variation type, n (\%) ${ }^{d}$} \\
\hline Pathogenic mutation & $633(93.8)$ \\
\hline Variant of unknown significance & $61(9.0)$ \\
\hline \multicolumn{2}{|c|}{ Time from TSC clinical diagnosis to molecular testing, months } \\
\hline Mean (SD) & $79.6(116.78)$ \\
\hline Median (range) & $22(0-721)$ \\
\hline Patients with prenatal diagnosis, n (\%) & $124(5.9)$ \\
\hline \multicolumn{2}{|l|}{ Biological mother/father evaluated for TSC, $n$} \\
\hline Mother & 865 \\
\hline Father & 753 \\
\hline \multicolumn{2}{|l|}{ TSC inherited from one parent, $\mathrm{n}$} \\
\hline Total & 290 \\
\hline Mother & 168 (95 clinically) \\
\hline Father & 122 (56 clinically) \\
\hline \multicolumn{2}{|l|}{ Patients with affected relatives, n (\%) } \\
\hline Total & $478(22.8)$ \\
\hline 1 & $259(12.4)$ \\
\hline 2 & $116(5.5)$ \\
\hline 3 & $54(2.6)$ \\
\hline$>3$ & $52(2.5)$ \\
\hline $\begin{array}{l}\text { Patients with at least one blood relative participating } \\
\text { in TOSCA, } \mathrm{n}(\%)\end{array}$ & 207 (9.9) \\
\hline
\end{tabular}

SD standard deviation, TSC tuberous sclerosis complex, TOSCA TuberOus SClerosis registry to increase disease Awareness

${ }^{a}$ Data available for 2054 patients; ${ }^{b}$ Information on the type of mutation was missing for 6 patients; 5 patients had both TSC1 and TSC2 mutations;

'Percentages calculated considering the number of patients with molecular testing as the denominator value. ${ }^{\mathrm{d}}$ The count $(\mathrm{n})$ includes 19 patients who had both variation types

\section{Renal manifestations}

Renal angiomyolipomas were reported in 987 (47.2\%; males, $42.5 \%$ and females, $57.5 \%$ ) patients and diagnosed at a mean age of 17.4 years (median age 13.0 years; range 0-67) (Table 2). The majority of angiomyolipomas (946 patients, 95.8\%) recorded at baseline were diagnosed prior to recruitment, most (792 patients, 83.7\%) of which were without any signs and symptoms at the time of assessment. Of the patients with ongoing lesions, 793
Table 2 Baseline manifestations of TSC reported in TOSCA

\begin{tabular}{|c|c|}
\hline Manifestations of TSC & $\begin{array}{l}\text { Patients at baseline, } \\
\mathrm{n}(\%)\end{array}$ \\
\hline \multicolumn{2}{|l|}{ Neurological } \\
\hline SEGA & $510(24.4)$ \\
\hline Cortical tuber & $1721(82.2)$ \\
\hline SEN & $1636(78.2)$ \\
\hline Cerebral white matter radial migration lines & $429(20.5)$ \\
\hline \multicolumn{2}{|l|}{ Renal } \\
\hline Renal angiomyolipoma & $987(47.2)$ \\
\hline Multiple renal cysts & $477(22.8)$ \\
\hline Polycystic kidneys & $73(3.5)$ \\
\hline Impaired renal function & $43(2.1)$ \\
\hline Renal malignancy & $24(1.1)$ \\
\hline \multicolumn{2}{|l|}{ Pulmonary } \\
\hline Lymphangioleiomyomatosis & $144(6.9)$ \\
\hline \multicolumn{2}{|l|}{ Cardiavascular } \\
\hline Cardiac rhabdomyoma & 717 (34.3) \\
\hline \multicolumn{2}{|l|}{ Dermatologic } \\
\hline$\geq 3$ hypomelanotic macules & $1399(66.8)$ \\
\hline Facial angiofibroma & $1199(57.3)$ \\
\hline Shagreen patch & $573(27.4)$ \\
\hline Ungual or periungual fibromas & $350(16.7)$ \\
\hline Forehead plaque & $295(14.1)$ \\
\hline Confetti lesions & $179(8.6)$ \\
\hline \multicolumn{2}{|l|}{ Ophthalmologic } \\
\hline Retinal hamartoma & $294(14.0)$ \\
\hline Epilepsy & $1748(83.5)$ \\
\hline
\end{tabular}

SEGA subependymal giant cell astrocytoma, SEN subependymal nodule, TOSCA TuberOus SClerosis registry to increase disease Awareness

(83.8\%) had bilateral angiomyolipomas, 829 (87.6\%) had multiple lesions, 329 (34.8\%) had angiomyolipoma lesions $>3 \mathrm{~cm}$ in diameter, and 396 (41.9\%) had both multiple and bilateral renal angiomyolipomas. The most common past medical history of signs/symptoms reported included pain (51 [5.4\%]), elevated blood pressure (48 [5.1\%]), impaired renal function (36 [3.8\%]), hemorrhage (47 [5\%]), and microscopic hematuria (35 [3.7\%]). Renal angiomyolipomas were treated in 274 $(27.8 \%)$ patients. Most common mode of treatment (monotherapy or in combination with other treatment modalities) was embolization (126 [46\%]) followed by mTOR inhibitors (110 [40.1\%]).

Among other renal features, multiple renal cysts were the most frequent (22.8\%) while polycystic kidneys (3.5\%), impaired renal function (non-angiomyolipoma related; $2.1 \%)$, and renal malignancy (1.1\%) were infrequently reported (Table 2). 
Table 3 TSC-Associated Neuropsychiatric Disorders (TAND) features reported in TOSCA at baseline

\begin{tabular}{|c|c|c|c|}
\hline TAND features & $\begin{array}{l}\text { Patients with manifestation, } \mathrm{n} / \text { patients } \\
\text { with available data }(\%)\end{array}$ & $\begin{array}{l}\text { Patients with available } \\
\text { data, } \mathrm{n} / 2093(\%)\end{array}$ & $\begin{array}{l}\text { Missing data } \\
\mathrm{n} / 2093(\%)\end{array}$ \\
\hline \multicolumn{4}{|l|}{ Behavioral difficulties } \\
\hline Overactivity & $317(20.7)$ & $1533(73.2)$ & $560(26.8)$ \\
\hline Sleep difficulties & $301(19.5)$ & $1540(73.6)$ & $553(26.4)$ \\
\hline Impulsivity & $297(19.4)$ & $1533(73.2)$ & $560(26.8)$ \\
\hline Anxiety & $205(13.7)$ & $1498(71.6)$ & $595(28.4)$ \\
\hline Mood swings & $201(13.4)$ & $1499(71.6)$ & $594(28.4)$ \\
\hline Severe aggression & $168(10.8)$ & $1559(74.5)$ & $534(25.5)$ \\
\hline Depression mood & $124(8.3)$ & $1500(71.7)$ & $593(28.3)$ \\
\hline Self-injury & $106(6.8)$ & $1555(74.3)$ & $538(25.7)$ \\
\hline Obsession & $92(6.1)$ & $1505(71.9)$ & $588(28.1)$ \\
\hline Psychosis & $34(2.3)$ & $1514(72.3)$ & $579(27.7)$ \\
\hline Hallucination & $23(1.5)$ & $1512(72.2)$ & $581(27.8)$ \\
\hline \multicolumn{4}{|l|}{ Psychiatric disorders } \\
\hline ASD & $291(20.7)$ & $1406(67.1)$ & $687(32.8)$ \\
\hline ADHD & 260 (19.6) & $1329(63.4)$ & $764(36.5)$ \\
\hline Anxiety & $118(9.1)$ & $1294(61.8)$ & 799 (38.2) \\
\hline Depression & $80(6.1)$ & $1301(62.1)$ & $792(37.8)$ \\
\hline \multicolumn{4}{|l|}{ Intellectual Ability ${ }^{a}$} \\
\hline Normal & $371(45.1)$ & NA & NA \\
\hline Mild ID & $232(28.2)$ & NA & NA \\
\hline Moderate ID & $123(15.0)$ & NA & NA \\
\hline Severe ID & $75(9.1)$ & NA & NA \\
\hline Profound ID & $21(2.6)$ & NA & NA \\
\hline \multicolumn{4}{|l|}{ Academic difficulties } \\
\hline Patients ever had difficulties in academic performance & $682(57.8)$ & $1179(56.3)$ & $914(43.7)$ \\
\hline Patients assessed for academic difficulties & 332 (48.6\% of those with reported difficulties) & $332(15.9)$ & NA \\
\hline \multicolumn{4}{|l|}{ Neuropsychological difficulties } \\
\hline Patients ever had any neuropsychological skill assessed & $510(40.1)$ & $1270(60.6)$ & $823(39.3)$ \\
\hline Patients with performance $<5^{\text {th }}$ percentile & $\begin{array}{l}281 \text { (55\% of those who had neuropsychological } \\
\text { assessment) }\end{array}$ & $281(13.4)$ & NA \\
\hline
\end{tabular}

ASD autism spectrum disorder, $A D H D$ attention deficit hyperactivity disorder, NA not applicable, TOSCA TuberOus SClerosis registry to increase disease Awareness, TAND TSC-associated neuropsychiatric disorders, ID Intellectual Disability

${ }^{a}$ Patients with intellectual ability measured by intellectual quotient were available in $822(39.3 \%)$ out of 834 patients. Intelligent ability was not measured in 752 (35.9\%) patients

\section{Pulmonary manifestations}

Lymphangioleiomyomatosis (LAM) was reported in 144 (6.9\%) patients of whom $142(98.6 \%)$ were adults $>18$ years (Table 2). Of these, 136 were females ( $\leq 18$ years, 2 [1.4\%]; $18-40$ years, 70 [51.4\%]; > 40 years, $64[47 \%])$ and 8 were males. Mean age at diagnosis was 36.7 years (median age 35.0 years; range 9-61). Almost all patients (142 of 144) were diagnosed with LAM when they were $>18$ years of age. LAM caused signs and/or symptoms in $58(40.3 \%)$ patients. The most common symptom was dyspnea (69\%), and lung collapse and/or pneumothorax (44.8\%). In the 46 patients who received treatment, mTOR inhibitors (23 patients, 50\%, alone or in combination with other treatment modalities) was most commonly used. Other treatment modalities included surgery, chest tube, chylous fluid drainage, and bronchodilators.

\section{Cardiovascular manifestations}

Cardiac rhabdomyomas, which were the most frequent cardiovascular manifestations found in 717 (34.3\%) patients (Table 2). These were diagnosed at a mean age of 3.1 years. Cardiac rhabdomyomas reported earlier and were still present in $483(67.4 \%)$ patients at the time of 
assessment, resolved spontaneously in 208 (29\%) patients, and resolved after treatment in 24 (3.3\%) patients. Among other cardiovascular features, arrhythmia/dysrhythmia and valve dysfunction were reported in 5.6 and $2.9 \%$ of patients, respectively. Aneurysm (1\%) and coarctation of aorta (0.2\%) were rarely reported.

\section{Dermatological and dental manifestations}

The most frequently reported dermatological manifestations were facial angiofibromas (1199 [57.3\%]). The median age at onset of facial angiofibroma was 6.0 years (range 0-67). Approximately, one-third (32.8\%) of the patients had received treatment. Common treatment modalities included laser therapy (49.1\%), topical mTOR inhibitors (23.2\%) and systemic mTOR inhibitors (21.1\%) used alone or in combination with other treatment modalities. Hypomelanotic macules $(\geq 3)$ were reported in $66.8 \%$ of patients (median age 1.0 year; range, 0-67). Other dermatological manifestations included shagreen patch (27.4\%), ungual or peri-ungual fibroma (16.7\%), forehead plaque (14.1\%), confetti lesions (8.6\%), and other dermatological conditions (17.2\%, angiomyolipoma [also known as a cutaneous angiolipoleiomyoma], cafe au lait macule, poliosis, and skin tags). Dental manifestations included randomly distributed pits in dental enamel $(98$ [4.7\%]) and gingival fibromas (96 [4.6\%]).

\section{Ophthalmological manifestations}

Retinal hamartomas, the most frequent ophthalmological manifestation, were reported in 294 (14\%) patients, and diagnosed at a mean age of 8.3 years (median age 5.0 years; range $0-50$ ). These were symptomatic in $12.6 \%$ of patients. Symptoms included blurred vision, constriction of visual field, and visual impairment. Retinal achromic patch (53 [2.5\%]) and other TSCrelated ophthalmological lesions (73 [3.5\%]) were also reported but less commonly.

\section{Other manifestations}

Liver hamartomas were reported in 190 (9.1\%) patients, with a higher frequency in female patients $(73.7 \%$ of those with liver hamartomas), and diagnosed at a mean age of 23.3 years (median age 22 years; range $0-61$ ). Both ongoing liver hamartoma and angiomyolipomas was reported in 168 patients.

Reproductive abnormalities were noted in a small number of patients and included menstrual cycle disorders $(67[6.2 \%]$ ), amenorrhea (female patients > 11 years, 38 [3.5\%]), abnormal onset of puberty (93 [4.4\%]), other abnormal reproductive conditions (49 [2.3\%]), abnormal hormone levels including prolactin (21 [1\%]), thyroid-stimulating hormone (145 [6.9\%]), follicle-stimulating hormone (37 [1.8\%]), testosterone (21 [1\%]), and luteinizing hormone (35 [1.7\%]).

Collectively, manifestations previously thought to be rare were reported in 316 (15.1\%) patients; bone sclerotic foci in 87 patients, scoliosis in 46 patients, thyroid adenoma in 15 patients, spleen angiomyolipoma in 5 patients, pancreatic neuroendocrine tumor in 5 patients, and hemihypertrophy (abnormal growth on one side of the body), calvarial sclerosis and thickening (each in 2 patients).

Co-morbidities were reported in 347 (16.6\%) patients; cardiovascular co-morbidities were the most frequent (44 patients). Other less common comorbidities included malignancies (15 patients), dyslipidemia (17 patients) and diabetes ( 5 patients). Other features of TSC reported were bone cysts (65 patients), non-renal hamartoma (excluding liver, 34 patients), and hamartomatous rectal polyps (8 patients).

\section{Manifestations of TSC across age groups in TOSCA Participants}

Figure 4 depicts a distinctive pattern to age-related emergence and prevalence of TSC manifestations. Hypomelanotic macules, subependymal nodules, cortical tubers and cardiac rhabdomyomas were reported from age $\leq 2$, (presumably as soon as they were looked for), and their prevalence did not change. In contrast, the prevalence of SEGAs and retinal hamartomas peaked in childhood, and the prevalence of renal angiomyolipomas, facial angiofibromas, forehead plaques and shagreen patches went on increasing into adulthood. However all these lesions were reported in a small number of patients from age $\leq 2$ years. In contrast, pulmonary LAM and ungual fibromas presented later but also became more prevalent in adults.

\section{Discussion}

The TOSCA natural history study represents the largest clinical collection of TSC data to date. It is not possible to derive an accurate absolute prevalence of TSC or its individual manifestations in the general population from this dataset because it was ascertained from a specialist clinic population. However, the data do record the relative prevalence of different manifestations within this cohort and their natural history. Reassuringly, our data shows a number of similarities to what has been reported in previous studies of TSC $[1,14]$. For instance, TSC2 mutations were more common than TSC1 mutations $[4,15]$ and the prevalence of certain disease features such as cortical tubers, subependymal nodules and epilepsy were similar to previous reports $[1,14]$. However, the frequencies of some of the other features such as SEGA, TAND, and renal angiomyolipomas differed from the published data $[1,14]$. Potential reasons for 


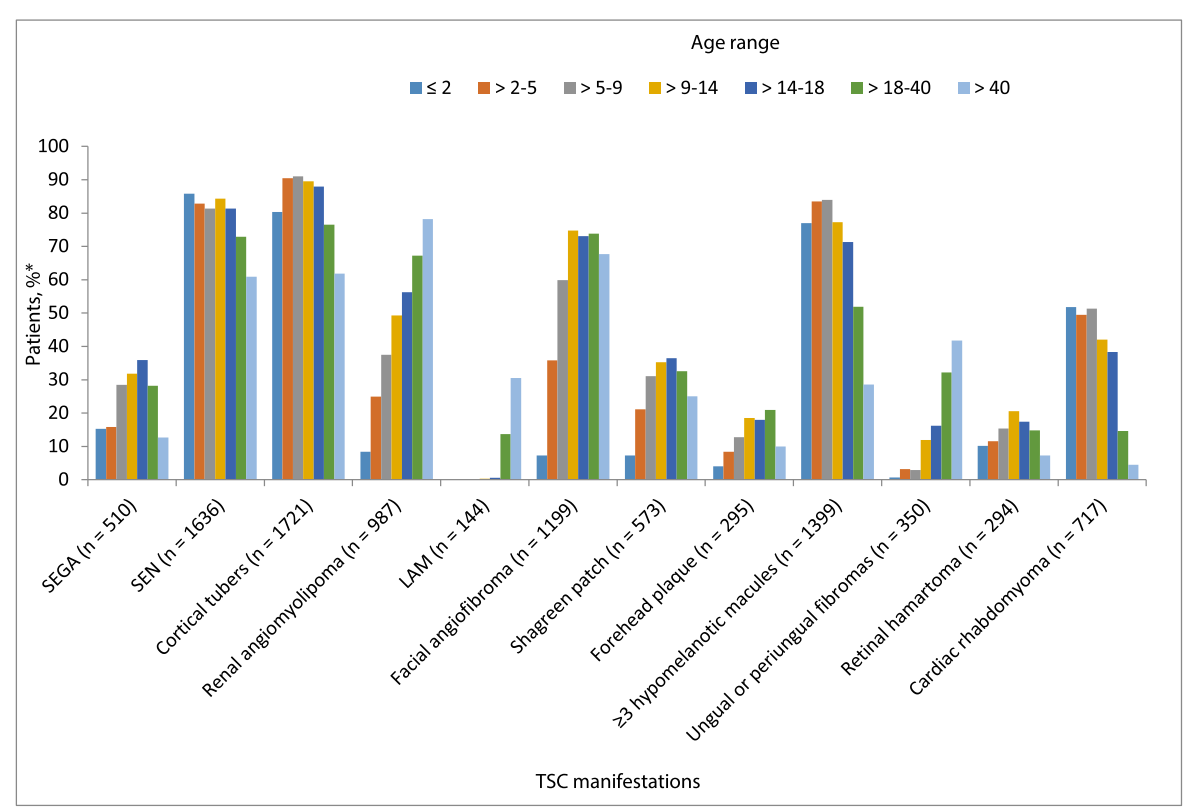

LAM, Lymphangioleiomyomatosis; SEGA, subependymal giant cell astrocytoma; SEN, subependymal nodule; TOSCA, TuberOus SClerosis registry to increase disease Awareness; TSC, tuberous sclerosis complex "Percentage of the manifestation in each age category is calculated based on the total number of patients under the respective age group.

Fig. 4 Major manifestations of TSC categorized by age range in TOSCA participants ( $N=2093)$. LAM, Lymphangioleiomyomatosis; SEGA, subependymal giant cell astrocytoma; SEN, subependymal nodule; TOSCA, TuberOus SClerosis registry to increase disease Awareness; TSC, tuberous sclerosis complex. *Percentage of the manifestation in each age category is calculated based on the total number of patients under the respective age group

these similarities and differences are discussed in more details below.

SEGAs were reported in $24.4 \%$ of the patients, which is much higher than the previously reported rate of 10$15 \%[1,11]$. The higher frequency of SEGAs seen in this cohort could be because the majority of centers included in TOSCA were specialist neurology centers. There also is ongoing discussion with respect to the most accurate definition of SEGA, which may have been of influence on the number of SEGA reported in TOSCA. In 2012, a European Consensus Group defined SEGA as a tumor in a TSC patient that is usually characterized by a location near the foramen of Monro, $>0.5 \mathrm{~cm}$ in diameter, with any documented growth, and gadolinium enhancement on neuroimaging [16]. Later that year, an international panel of experts defined SEGA as a lesion at the caudothalamic groove with either a size of more than $1 \mathrm{~cm}$ in any direction or a subependymal lesion at any location that has shown serial growth on consecutive imaging regardless of size [17]. Most SEGAs show avid enhancement after contrast administration; however, a growing subependymal lesion even in the absence of enhancement should be considered a SEGA [17]. Median age at SEGA diagnosis was 8 years but more than a quarter of patients were diagnosed with SEGA already before age two years, highlighting the young age at onset and early need for follow-up. When compared to the last scan, $36.7 \%$ of ongoing SEGAs were reported to have grown in size. Since SEGAs are known to grow over time, there are existing recommendations for their regular follow-up and timely management $[10,16]$. Median time between scans was 1 year and median time between SEGA diagnosis and start of treatment was less than 1 year, reflecting good clinical practice with respect to SEGA follow-up and management in the TOSCA cohort. Although SEGA growth was most common between ages 5-18 years, growth after age 18 years remains possible as was shown in this cohort. This highlights the necessity to stay vigilant to possible symptoms related to SEGA-growth also at adult age. In this analysis, surgery was the most common mode of treatment for SEGAs followed by mTOR inhibitors. Until the recent approval of everolimus for the treatment of SEGAs associated with TSC $[9,18]$, surgery was the only treatment option. For acutely symptomatic SEGAs, surgery and cerebrospinal fluid diversion remain the treatment of choice [10]. However, for asymptomatic growing SEGAs, mTOR inhibitors may be considered especially in multisystem disease [10], since mTOR inhibitors have also been found to benefit other manifestations of TSC [19-23]. Due to high rate of regrowth of residual tumors [24], mTOR inhibitors should be recommended for 
those patients with SEGA, in whom total surgical removal of SEGA is not possible. Complete SEGA resection might be more difficult to achieve in the presence of bilateral SEGA [17], which were present in over one third of patients in this cohort.

Similar to previous reports [3], this analysis of TOSCA data showed that epilepsy (83.5\%) was the most commonly reported clinical presentation of TSC. Focal seizures were the most common type of seizures followed by infantile spasms. GABAergics (vigabatrin) were most frequently used, both for focal seizures and for infantile spasms. This finding is in line with European recommendations made by TSC Consensus meeting for SEGA and epilepsy management in 2012, which recommended vigabatrin both for infantile spasms and focal seizures in infants in the first year of life [25]. Also the guidelines from the 2012 International TSC consensus Conference recommend vigabatrin as first line and adrenocorticotropic hormone as the second line treatment for infantile spasms in individuals with TSC [10]. The use of other anti-epileptic drugs; e.g., sodium channel blockers and fructose derivatives will be described in more detail in a subsequent paper. Despite a high rate of refractory epilepsy, alternative treatment options such as the ketogenic diet and epilepsy surgery were not commonly used in this population.

Recently, mTOR inhibitors have been thought to be useful for the treatment of refractory seizures [26-28]. Results from a phase III, randomized, double-blind, placebo-controlled study (EXIST-3; NCT01713946) could tell us the efficacy and safety of 2 trough-ranges of everolimus (an mTOR inhibitor) as adjunctive therapy in patients with TSC who have refractory seizures.

The TAND domain showed lower rates of behavioral and psychiatric disorders than previously reported [29-31]. The rates of intellectual disability were similar to previous reports $[29,30]$ but there was no clear evidence of a bimodal distribution of IQ/DQ. Very high rates of academic difficulties and of neuropsychological deficits were reported, and represent the first report of the potential magnitude of academic and neuropsychological deficits in TSC. Strikingly though, diagnoses of ASD, ADHD, anxiety and depression were made very late, and the TAND domain was characterized by very high rates of missing data. These findings suggest that, even in the TOSCA cohort, TAND is underdiagnosed and therefore undertreated. A major challenge in maintaining a database like TOSCA is to ensure that data are complete, especially since these are collected from many centers over a long time period. Missing data for TAND suggests that a considerable number of patients were never assessed for TAND. It is apparent that there is a specific need to educate clinicians to assess all the patients with TSC for TAND. In order to address the need, to increase the awareness of TAND and the importance of screening for these difficulties, the Neuropsychiatry Panel at the 2012 Tuberous Sclerosis Complex International Consensus Conference developed a simple tool called the TAND checklist [31, 32]. The neuropsychiatry panel recommended at least an annual screening for TAND and comprehensive formal evaluation for TAND at key developmental time points: infancy (0-3 years), preschool (3-6 years), pre-middle school (6-9 years), adolescence (12-16 years), early adulthood (18-25 years), and as needed thereafter. Management strategies should be based on the TAND profile of each patient and should be based on evidence-based good practice guidelines/practice parameters for individual disorders (e.g., autism spectrum disorder, attention deficit hyperactivity disorder, anxiety disorder). The TAND checklist can serve as an ideal guide to facilitate the discussion between the healthcare professionals and patients [31].

The lower rate of renal angiomyolipomas reported in this population was likely attributable to the fact that the cohort had a younger median age. This is clear from Fig. 4 that the prevalence in adults (e.g., $80 \%$ in age $>40$ ) is the same as in other studies. Also, the lower than expected prevalence of complications of angiomyolipoma such as hypertension, microscopic hematuria, and impaired renal function (reported in the literature as $27,25-50$, and $40 \%$ respectively) [33-35] reported here is a reflection of the young age of this cohort, who have not had time to develop the most common adult renal complications; and to good practice in specialist clinics of active surveillance and pre-emptive treatment of enlarging angiomyolipomas. The finding that $27.8 \%$ of those with angiomyolipomas had received treatment for them (presumably mostly pre-emptive) supports this suggestion. An important finding is that a significant number of children ( 55 patients aged $<18$ years) needed intervention for their angiomyolipomas. It is also of note that the occurrence of angiomyolipomas was not statistically different in women compared to men. A previous report [36] found angiomyolipomas complications were more common in women than men, and two thirds of the recruits for EXIST-2 [8] were women; both findings implying that if there is no sex difference in angiomyolipomas prevalence, women are more vulnerable to developing complications. Renal angiomyolipomas can cause considerable morbidity including complications like aneurysm and hemorrhage [37]. Moreover, renal complications have been associated with the most common cause for death in adult 
patients with TSC [38]. Timely diagnosis and treatment are therefore of utmost importance. The main objective in treating renal angiomyolipomas is to prevent hemorrhage and to preserve renal function. TSC Consensus Conference guidelines recommend embolization followed by corticosteroids as the firstline of treatment for angiomyolipomas presenting with acute hemorrhage [10]. An mTOR inhibitor is the recommended first-line therapy for asymptomatic, growing angiomyolipoma $>3 \mathrm{~cm}$ in diameter [10]. In this cohort, renal angiomyolipomas were most commonly treated with embolization followed by mTOR inhibitors.

LAM is the main pulmonary manifestation of TSC, which is seen in about $40 \%$ of women of reproductive age $[39,40]$. A recent study has reported a higher prevalence (up to $80 \%$ ), especially in women over 40 years of age [39]. In this dataset, LAM was reported much less frequently compared to what has been published in literature. This could probably be explained partly by the young average age of the cohort and probably also because screening may have been based on clinical symptoms rather than high-resolution chest computed tomography (HRCT). However $40 \%$ of these patients were symptomatic from their LAM. Cudzilo et al. reported that most women with TSC develop cystic changes consistent with LAM [39], highlighting the importance of routine surveillance using CT scan. As per the guidelines, baseline pulmonary function testing and HRCT must be performed in females 18 years or older, even if asymptomatic [10]. Screening for LAM in female patients and adult males (symptomatic) with TSC as per the recommendations would be helpful. The high occurrence of symptomatic retinal hamartomas $(12.6 \%)$ is a new finding and has implications for surveillance. In this analysis of TOSCA, it was also noted that most of the patients were asymptomatic. It is therefore crucial to highlight the importance of regular surveillance in all patients with TSC even in the absence of symptoms to help prevent complications.

With regard to the age at occurrence, most of the manifestations in majority of the patients were diagnosed at the median age of 1 year. The mean age at diagnosis for cardiac rhabdomyoma was 3.1 years. The highest incidence of cardiac tumors is in children below 2 years of age reaching up to $65-80 \%$ [40]. This late age at diagnosis of cardiac rhabdomyomas could be related to age at diagnosis of TSC. Apart from those diagnosed with rhabdomyomas on fetal ultrasonography, other patients may have had an echocardiogram organized after their diagnosis of TSC was made.

Early, sometimes prenatal, diagnosis of TSC enables the beginning of surveillance and thus prevention or amelioration of complications such as epilepsy, intellectual disability, autistic behaviors and tumors development $[17,41,42]$. As TSC is a genetic disease, the family members must also be assessed. Family counselling must be done and genetic testing carried out [10]. Current molecular techniques enable the TSC1/TSC2 mutation detection in more than $95 \%$ of patients [4]. In TOSCA participants, genetic testing was not reported in about $40 \%$ of the patients, which might be due to ethical or financial reasons. Five patients reported both TSC1 and TSC2 mutations, this unexpected finding is being investigated and will be reported in more detail in future publications.

Though TOSCA is a large clinical case series, it must be noted that patients were recruited through clinical centers with expertise in TSC and milder cases may not always be seen at these centers. The study design therefore includes potential limitations inherent to clinical case series, albeit large-scale, multinational ones. Nevertheless, participation of a large number of centers with complementary expertise has helped inclusion of a huge number of patients with TSC, which reveals occurrence rates of complications that are likely to be representative of hospital clinical practice. This baseline paper of TOSCA provides a detailed description of the disease trajectory of TSC. The registry can provide valuable insights into the necessity for monitoring, the timing, and the indications for treatment of this disease. Further follow-up studies of TOSCA including research projects will provide more detail in understanding the treatment interventions and outcomes.

\section{Conclusion}

This international registry provides a better understanding of the TSC manifestations, and facilitates development of better management and surveillance strategies for patients with TSC. Following patients over the years will help in understanding any changes in the treatment and outcome of the different manifestations. Baseline analysis has highlighted the serious import of epilepsy and SEGA in children, and renal angiomyolipomas in children as well as adults. We found inadequate surveillance for TAND; hopefully this will be improved in future by widespread adoption of the international guidelines including use of the TAND checklist. Clinicians need to be alert for rare complications but especially changes in retinal hamartomas. We believe comprehensive surveillance will lead to more pro-active pre-emptive treatment and better outcomes in future. Subsequent analyses are planned yearly to allow the clinical course of the disease over time to be evaluated. 


\section{Additional file}

Additional file 1: TableS1. Age and Gender Distribution of TSC manifestations reported in TOSCA. (DOCX $13 \mathrm{~kb}$ )

\section{Abbreviations}

ACTH: Adrenocorticotropic hormone; ADHD: Attention deficit hyperactivity disorder; ASD: Autism spectrum disorder; GABA: Gammaaminobutyric acid; HRCT: High-resolution chest computed tomography; LAM: Lymphangioleiomyomatosis; mTOR: Mammalian target of rapamycin; SEGA: Subependymal giant cell astrocytoma; TAND: TSC-associated neuropsychiatric disorders; TOSCA: TuberOus SClerosis registry to increase disease Awareness; TSC: Tuberous sclerosis complex

\section{Acknowledgements}

We thank patients and their families, investigators, and staff from all the participating sites. We thank Rama Mylapuram, Pharm D, Novartis Healthcare Pvt. Ltd. for providing medical editorial assistance with this manuscript.

\section{Funding}

This study was funded by Novartis Pharma AG. Novartis funded; meetings of the principal investigators to design the study, research costs including the cost of the database, and extraction of data for analysis. The principal investigators undertook detailed analysis and interpretation of the findings. Novartis funded writing of the first draft of the manuscript, the principle investigators reperesented by the TOSCA scientific advisory board were then responsible for revising and completing the manuscript and for the validity of the data interpretation as described above in authors contributions. The study participants have not received funds for their participation in the study.

\section{Availability of data and materials}

The dataset supporting the conclusions of this article are included within the article itself.

\section{Authors' contributions}

JCK was responsible for designing the study, patient accrual, clinical care, data interpretation, drafting, revising, final review, and approval of the manuscript. GBd'A was responsible for designing the study, data interpretation, drafting, revising, final review, and approval of the manuscript. EIB was responsible for designing the study, patient accrual, clinical care, data interpretation, drafting, revising, final review, and approval of the manuscript. JCF was responsible for designing the study, patient accrual, clinical care, data interpretation, drafting, revising, final review, and approval of the manuscript. TC was responsible for designing the study, data interpretation, drafting, revising, final review, and approval of the manuscript. RC was responsible for designing the study, patient accrual, trial management, data collection, trial statistician, data analysis, data interpretation, drafting, revising, final review, and approval of the manuscript. VC was responsible for designing the study, data interpretation, drafting, revising, final review, and approval of the manuscript. PC was responsible for designing the study, patient accrual, clinical care, data interpretation, drafting, revising, final review, and approval of the manuscript. MD was responsible for designing the study, patient accrual, clinical care, data interpretation, drafting, revising, final review, and approval of the manuscript. PJdeV was responsible for designing the study, data interpretation, drafting, revising, final review, and approval of the manuscript. MF was responsible for designing the study, patient accrual, clinical care, data interpretation, drafting, revising, final review, and approval of the manuscript. CF was responsible for designing the study, data interpretation, drafting, revising, final review, and approval of the manuscript. GG was responsible for designing the study, patient accrual, trial management, data collection, trial statistician, data analysis, data interpretation, drafting, revising, final review, and approval of the manuscript. $\mathrm{CH}$ was responsible for designing the study, patient accrual, clinical care, data interpretation, drafting, revising, final review, and approval of the manuscript. SJ was responsible for designing the study, patient accrual, clinical care, data interpretation, drafting, revising, final review, and approval of the manuscript. JAL was responsible for designing the study, patient accrual, clinical care, data interpretation, drafting, revising, final review, and approval of the manuscript. AM was responsible for designing the study, patient accrual, clinical care, data interpretation, drafting, revising, final review, and approval of the manuscript. RN was responsible for designing the study, patient accrual, clinical care, data interpretation, drafting, revising, final review, and approval of the manuscript. FO'C was responsible for designing the study, data interpretation, drafting, revising, final review, and approval of the manuscript. MPB was responsible for designing the study, patient accrual, clinical care, data interpretation, drafting, revising, final review, and approval of the manuscript. JQ was responsible for designing the study, data interpretation, drafting, revising, final review, and approval of the manuscript. RM was responsible for designing the study, patient accrual, trial management, data collection, trial statistician, data analysis, data interpretation, drafting, revising, final review, and approval of the manuscript. VS was responsible for designing the study, patient accrual, clinical care, data interpretation, drafting, revising, final review, and approval of the manuscript. MS was responsible for designing the study, patient accrual, clinical care, data interpretation, drafting, revising, final review, and approval of the manuscript. YT was responsible for designing the study, data interpretation, drafting, revising, final review, and approval of the manuscript. RT was responsible for designing the study, patient accrual, clinical care, data interpretation, drafting, revising, final review, and approval of the manuscript. SY was responsible for designing the study, data interpretation, drafting, revising, final review, and approval of the manuscript. BZ was responsible for designing the study, patient accrual, clinical care, data interpretation, drafting, revising, final review, and approval of the manuscript. ACJ was responsible for designing the study, patient accrual, clinical care, data interpretation, drafting, revising, final review, and approval of the manuscript.

\section{Competing interests}

$\mathrm{RC}, \mathrm{GG}$, and MR are employees of Novartis. All authors are members of TOSCA Scientific Advisory Board and have received honorarium from Novartis. JCK and BZ report receiving grants from Novartis. ACJ, SJ, and VC received lecture fees from Novartis. MS has received personal fees for consultancy activities and lectures and financial support for investigator driven research from Novartis. PJdV has been a co-principal investigator on research studies funded by Novartis.

\section{Consent for publication}

All patients were informed that the reason for enrolling in the study was to collect natural history data for scientific analysis and publication (an obligation mandated by the Good Clinical Practice guidelines) and they signed consent forms with that understanding.

\section{Ethics approval and consent to participate}

All patients (or their legal representatives) provided written informed consent before enrolling in the TOSCA disease registry. The study was designed, implemented, and reported in accordance with the principles of Good Clinical Practice, Good Pharmacoepidemiology Practices of the International Society for Pharmacoepidemiology (ISPE 2008), the STROBE (Strengthening and Reporting of Observational Studies in Epidemiology) guidelines, and the ethical principles laid down in the Declaration of Helsinki, and all local regulations. The study protocol and all amendments were reviewed and approved by independent ethics committee/institutional review board for each center (National Hospital Organization Central Ethics Committee; Gazi University Clinical Research Ethics Committee; Independent Multidisciplinary Committee on Ethical Review of Clinical Trials; Peking Union Medical College Hospital; Commissie Medische Ethiek UZ Brussel; CNIL (Commission National de l'Informatique et des Libertés), CCTIRS (Comité Consultatif sur le traitement de l'information en matière de recherche dans le domaine de la santé); Comité Etico Investigación Clínica de Euskadi (CEIC-E); Consejeria de Salud y Bienestar Social, Dirección General de Calidad, Investigación, Desarrollo e Innovación, Comité Coordinador de Ética de la Investigación Biomédica de Andalucía; Research Ethics Committee of the University of Tartu (UT REC); National Bioethics Committee of Medicine and of Medical Devices; Ethikkommission der Medizinischen Universität Graz; North Wales REC - West; Regionala Etikprövningsnämnden i Göteborg; REK - Regionale komiteer for medisinsk og helsefaglig forskningsetikk; Komisja Bioetyczna przy Instytucie "Pomnik Centrum Zdrowia Dziecka"; Ethikkommission bei der, Ludwig-MaximiliansUniversitat Monchen; Hokkaido University Hospital Independent clinical research Institutional Ethics Committee; Medical Juntendo University Institutional Ethics Committee; Nationak Center for Chile Health and Deveropment of IRB; Osaka University Hospital of IRB; Ethics Committee at Moscow Institute of Pediatrics and Pediatric Surgery; Peking University 
First Hospital; Chinese PLA general hospetal; Sanbo Brain Hospital Capital Medical University; Tianjin Children's Hospital; Childrens Hospital Of Fudan University; Zhongshan Hospital Fudan University; Fudan University Shanghai Cancer Center; The Second Affiliated Hospital of Guangzhou Medical University; The First Affiliated Hospital, Sun Yan-Sen University; The First Affiliated Hospital Of Guangzhou Medical University; Shenzhen Children's Hospital; West China Hospital, Sichuan University; Xijing Hospital; Children's Hospital of Chongqing Medical University; Wuhan Children's Hospital; The second affiliated hospital of Xi'an jiaotong university; Guangdong 999 brain hospital; Seoul National University Hospital Institutional Review Board; National Taiwan University Hospital (NTUH) Research Ethics Committee (REC); Institutional Review Board of the Taichung Veterans General Hospital; Institutional Review Board of Chung Shan Medical University Hospital; Institutional Review Board, Tungs' Taichung MetroHarbor Hospital; Institutional Review Board of National Cheng Kung University Hospital; Metro South Human Research Ethics Committee; Sydney Children's Hospital Network Human Research Ethics Committee; St Vincents Hospital Human Research Ethics Committee; Royal Melbourne Hospital Human Research Ethics Committee; Siriraj Institutional Review Board; Institutional Review board; The committee on Human Rights Related to Research Involving Human Subjects; The Institutional Review Board; Research Ethics Committee; Research and Development; Human Research Ethics Committee; Shaare Zedek Meidcla center Helsinki comittee; Sheba Medical center Helsinki comittee; Tel Aviv Sourasly Medical center Helsinki comittee; General University Hospital of Patras Ethics Committee; Pendeli Children's Hospital Ethics Committee; General University Hospital of Athens'G. Gennimatas Ethics Committee; Evaggelismos General Hospital Ethics Committee; General University Hospital of Thessaloniki "AHEPA" Ethics Committee; General University Hospital of Ionnina Ethics Committee; METC UMC Utrecht; Comité Ético de Investigación Clínica Hospital Infantil Universitario Niño Jesús, Dirección General de Ordenación e Inspección, Consejería de Sanidad Comunidad de Madrid, Servicios de Control Farmacéutico y Productos Sanitarios; Comité Ético de Investigación Clínica Fundació Sant Joan de Déu, Generalitat de Catalunya. Departament de Salut, Direcció General de Regulació, Planificació i Recursos Sanitaris; Comité Ético de Investigación Clínica del Hospital Universitario Vall d'Hebron de Barcelona, Generalitat de Catalunya. Departament de Salut, Direcció General de Regulació, Planificació i Recursos Sanitaris; Comité Ético de Investigación Clínica Hospital Universitario La Paz, Dirección General de Ordenación e Inspección, Consejería de Sanidad Comunidad de Madrid, Servicios de Control Farmacéutico y Productos Sanitarios; Comité Etico Investigación Clínica del Hospital Universitario y Politécnico de La Fe, Dirección General de Farmàcia i Productes Sanitaris, Generalitat de Valencia; Comité de Ética de la Investigación de Centro de Granada, Consejeria de Salud y Bienestar Social, Dirección General de Calidad, Investigación, Desarrollo e Innovación, Comité Coordinador de Ética de la Investigación Biomédica de Andalucía; Instituto Aragonés de Ciencias de la Salud (IACS), Comité Ético Investigación Clínica de Galicia; Comité Etico Investigación Clínica Regional del Principado de Asturias, Dirección General de Asistencia Sanitaria, Consejería de Sanidad, Gobierno del Principado de Asturias; Comité Etico Investigación Clínica Hospital 12 de Octubre, Dirección General de Ordenación e Inspección, Consejeria de Sanidad Comunidad de Madrid, Servicios de Control Farmacéutico y Productos Sanitarios; Comité Etico Investigación Clínica Hospital Universitario Virgen de la Arrixaca, Dirección General de Planificación, Ordenación Sanitaria y Farmacéutica e Investigación, Consejeria de Sanidad y Política Social Región de Murcia; Sección de Ordenación e Inspección Farmacéutica Departamento de Salud; Comité Ético de Investigación Clínica del Hospital Universitario del Río Hortega de Valladolid, Consejería de Sanidad, Dirección General de Salus Pública, Junta de Castilla León; Comissão de Ética para a Saúde (CES), Centro Hospitalar de Lisboa Ocidental, EPE; Comissão de Ética para a Saúde (CES), Centro Hospitalar do Porto, E.P.E.; Comissão de Ética para a Saúde (CES), Centro Hospitalar Lisboa Central, EPE; Comissão de Ética para a Saúde (CES), Hospital Garcia de Orta, EPE; Comissão de Ética para a Saúde (CES), Centro Hospitalar de São João, EPE; Comissão de Ética para a Saúde (CES), Hospital Professor Doutor Fernando Fonseca, EPE; Comissão de Ética para a Saúde (CES), Centro Hospitalar do Algarve, EPE (Unidade de Faro); LUHS Kaunas Regional Biomedical Research Ethics Committee; Paula Stradina klīniskās universitātes slimnīcas, Attīstibas biedrïbas Klīniskās izpētes Ëtikas komiteja, Ethics Committee for Clinical Research; Komisija Republike Slovenije za medicinsko etiko; Comitato Etico Indipendente Presso La Fondazione Ptv Policlinico Tor Vergata Di Roma;
Comitato Etico Interaziendale Milano Area A c/o O Azienda Ospedaliera Ospedale Luigi Sacco; Comitato Etico Regione Calabria Sezione Centro c/o A.O.U. Mater Domini Di Catanzaro; Comitato Etico Azienda Ospedaliera Universitaria Di Cagliari; Comitato Etico Cardarelli-Santobono c/o Ao Cardarelli; Comitato Etico Per La Sperimentazione Clinica Delle Province Di Verona E Rovigo, Presso Aoui Verona; Eticka Komise Fn Brno; Eticka Komisia Dfnsp Bratislava; Eticka Komisia Pri Dfn Kosice; Eticka Komisia Bratislavskeho Samospravneho Kraja).

\section{Author details}

'Sussex Kidney Unit, Royal Sussex County Hospital, Eastern Road, Brighton BN2 5BE, UK. ${ }^{2}$ Association Sclérose Tubéreuse de Bourneville, Gradignan, France. ${ }^{3}$ Moscow Institute of Pediatrics and Pediatric Surgery, Moscow, Russian Federation. ${ }^{4}$ Centro Hospitalar Lisboa Ocidental, Lisbon, Portugal. ${ }^{5}$ TSA Tuberous Sclerosis Association, Nottingham, UK. ${ }^{6}$ Novartis Farmacéutica SA, Gran Vía Corts Catalanes, Barcelona, Spain. 'Hôpital Louis Pradel, Claude Bernard University Lyon 1, Lyon, France. ${ }^{8}$ Tor Vergata University Hospital, Rome, Italy. ${ }^{9}$ Karolinska University Hospital, Stockholm, Sweden. ${ }^{10}$ Division of Child and Adolescent Psychiatry, University of Cape Town, Cape Town, South Africa. ${ }^{11}$ Universitätsklinik für Kinder-und Jugendheilkunde, Vienna, Austria. ${ }^{12}$ Associazione Sclerosi Tuberosa ONLUS, Milan, Italy. ${ }^{13}$ European Tuberous Sclerosis Complex Association, In den Birken, Dattein, Germany. ${ }^{14}$ Novartis Farma S.p.A, Origgio, Italy. ${ }^{15}$ Vivantes-Klinikum Neukölln, Berlin, Germany. ${ }^{16}$ Department of Child Neurology, Warsaw Medical University, Warsaw, Poland. ${ }^{17}$ The Tuberous Sclerosis Multidisciplinary Management Clinic, Sydney Children's Hospital, Randwick, NSW, Australia. ${ }^{18}$ Hospital Universitari Vall d'Hebron, Barcelona, Spain. ${ }^{19}$ Department of pediatric neurology, Necker Enfants Malades Hospital, Paris Descartes University, Paris, France. ${ }^{20}$ Institute of Child Health, University College London, London, UK. ${ }^{21}$ SPS Pediatrična Klinika, Ljubljana, Slovenia. ${ }^{22}$ Department of Pediatrics, Peking University People's Hospital (PKUPH), Beijing, China. ${ }^{23}$ Tallinn Children Hospital, Tallinn, Estonia. ${ }^{24}$ Klinikverbund Kempten-Oberallgäu gGmbH, Kempten, Germany. ${ }^{25}$ National Epilepsy Center, Shizuoka Institute of Epilepsy and Neurological Disorders, NHO, 886 Urushiyama Aoi-ku, Shizuoka, Japan. ${ }^{26}$ Hôpital Nord, Saint Etienne, France. ${ }^{27 " S t . ~ S o p h i a " ~ C h i l d r e n ' s ~ H o s p i t a l, ~ A t h e n s, ~ G r e e c e . ~}$ ${ }^{28}$ University Medical Center, Utrecht, Netherlands. ${ }^{29}$ UZ Brussel VUB, Brussels, Belgium.

Received: 16 July 2016 Accepted: 9 December 2016 Published online: 05 January 2017

\section{References}

1. Curatolo P, Bombardieri R, Jozwiak S. Tuberous sclerosis. Lancet. 2008;372: 657-68.

2. Osborne JP, Fryer A, Webb D. Epidemiology of tuberous sclerosis. Ann N Y Acad Sci. 1991;615:125-7.

3. Crino PB, Nathanson KL, Henske EP. The tuberous sclerosis complex. N Engl J Med. 2006;355:1345-56.

4. Tyburczy ME, Dies KA, Glass J, Camposano S, Chekaluk Y, Thorner AR, Lin L, Krueger D, Franz DN, Thiele EA, et al. Mosaic and intronic mutations in TSC1/TSC2 explain the majority of TSC patients with No mutation identified by conventional testing. PLoS Genet. 2015;11:e1005637.

5. Huang J, Manning BD. The TSC1-TSC2 complex: a molecular switchboard controlling cell growth. Biochem J. 2008;412:179-90.

6. Borkowska J, Schwartz RA, Kotulska K, Jozwiak S. Tuberous sclerosis complex: tumors and tumorigenesis. Int J Dermatol. 2011;50:13-20.

7. Bissler JJ, Kingswood JC, Radzikowska E, Zonnenberg BA, Frost M, Belousova E, Sauter M, Nonomura N, Brakemeier S, de Vries PJ, et al. Everolimus for renal angiomyolipoma in patients with tuberous sclerosis complex or sporadic lymphangioleiomyomatosis: extension of a randomized controlled trial. Nephrol Dial Transplant. 2016;31(1):111-9.

8. Bissler JJ, Kingswood JC, Radzikowska E, Zonnenberg BA, Frost M, Belousova E, Sauter M, Nonomura N, Brakemeier S, de Vries PJ, et al. Everolimus for angiomyolipoma associated with tuberous sclerosis complex or sporadic lymphangioleiomyomatosis (EXIST-2): a multicentre, randomised, double-blind, placebo-controlled trial. Lancet. 2013;381:817-24.

9. Franz DN, Belousova E, Sparagana S, Bebin EM, Frost M, Kuperman R, Witt O, Kohrman MH, Flamini JR, Wu JY, et al. Everolimus for subependymal giant cell astrocytoma in patients with tuberous sclerosis complex: 2-year open-label extension of the randomised EXIST-1 study. Lancet Oncol. 2014;15:1513-20. 
10. Krueger DA, Northrup $\mathrm{H}$, International Tuberous Sclerosis Complex Consensus $\mathrm{G}$. Tuberous sclerosis complex surveillance and management: recommendations of the 2012 international tuberous sclerosis complex consensus conference. Pediatr Neurol. 2013:49:255-65.

11. Kingswood JC, Bruzzi P, Curatolo P, de Vries PJ, Fladrowski C, Hertzberg C, Jansen AC, Jozwiak S, Nabbout R, Sauter M, et al. TOSCA - first international registry to address knowledge gaps in the natural history and management of tuberous sclerosis complex. Orphanet J Rare Dis. 2014;9:182.

12. Roach ES, Gomez MR, Northrup H. Tuberous sclerosis complex consensus conference: revised clinical diagnostic criteria. J Child Neurol. 1998;13:624-8.

13. Leiden Open Variation Database (LOVD): Tuberous sclerosis database. Available from: http://chromium.lovd.nl/LOVD2/TSC. Accessed 30 Aug 2016.

14. Wang S, Fallah A. Optimal management of seizures associated with tuberous sclerosis complex: current and emerging options. Neuropsychiatr Dis Treat. 2014;10:2021-30.

15. Dabora SL, Jozwiak S, Franz DN, Roberts PS, Nieto A, Chung J, Choy YS, Reeve MP, Thiele E, Egelhoff JC, et al. Mutational analysis in a cohort of 224 tuberous sclerosis patients indicates increased severity of TSC2, compared with TSC1, disease in multiple organs. Am J Hum Genet. 2001;68:64-80.

16. Jozwiak S, Nabbout R, Curatolo P, participants of the TSCCMfS, Epilepsy M. Management of subependymal giant cell astrocytoma (SEGA) associated with tuberous sclerosis complex (TSC): Clinical recommendations. Eur J Paediatr Neurol. 2013;17:348-52.

17. Roth J, Roach ES, Bartels U, Jozwiak S, Koenig MK, Weiner HL, Franz DN, Wang HZ. Subependymal giant cell astrocytoma: diagnosis, screening, and treatment. Recommendations from the international tuberous sclerosis complex consensus conference 2012. Pediatr Neurol. 2013;49:439-44.

18. European Medicines Agency. Votubia ${ }^{\oplus}$ (everolimus): Summary of opinion. 2012. Available from: -http://www.ema.europa.eu/docs/en_GB/document library/Summary_of_opinion/human/002311/WC500132883.pdf. Accessed 4 Dec 2015.

19. Cappellano AM, Senerchia AA, Adolfo F, Paiva PM, Pinho R, Covic A, Cavalheiro S, Saba N. Successful everolimus therapy for SEGA in pediatric patients with tuberous sclerosis complex. Childs Nerv Syst. 2013;29:2301-5.

20. Curatolo P, Moavero R. mTOR inhibitors in tuberous sclerosis complex. Curr Neuropharmacol. 2012:10:404-15.

21. Davies DM, de Vries PJ, Johnson SR, McCartney DL, Cox JA, Serra AL, Watson PC, Howe CJ, Doyle T, Pointon K, et al. Sirolimus therapy for angiomyolipoma in tuberous sclerosis and sporadic lymphangioleiomyomatosis: a phase 2 trial. Clin Cancer Res. 2011;17:4071-81.

22. Kohrman $\mathrm{MH}$. Emerging treatments in the management of tuberous sclerosis complex. Pediatr Neurol. 2012:46:267-75.

23. McCormack FX, Inoue Y, Moss J, Singer LG, Strange C, Nakata K, Barker AF, Chapman JT, Brantly ML, Stocks JM, et al. Efficacy and safety of sirolimus in lymphangioleiomyomatosis. N Engl J Med. 2011;364:1595-606.

24. Kotulska K, Borkowska J, Roszkowski M, Mandera M, Daszkiewicz P, Drabik K, Jurkiewicz E, Larysz-Brysz M, Nowak K, Grajkowska W, et al. Surgical treatment of subependymal giant cell astrocytoma in tuberous sclerosis complex patients. Pediatr Neurol. 2014;50:307-12.

25. Curatolo P, Jozwiak S, Nabbout R, SEGA TSCCMf, Epilepsy M. Management of epilepsy associated with tuberous sclerosis complex (TSC): clinical recommendations. Eur J Paediatr Neurol. 2012;16:582-6.

26. Krueger DA, Wilfong AA, Holland-Bouley K, Anderson AE, Agricola K, Tudor C, Mays M, Lopez CM, Kim MO, Franz DN. Everolimus treatment of refractory epilepsy in tuberous sclerosis complex. Ann Neurol. 2013;74:679-87.

27. Muncy J, Butler IJ, Koenig MK. Rapamycin reduces seizure frequency in tuberous sclerosis complex. J Child Neurol. 2009;24:477.

28. Perek-Polnik M, Jozwiak S, Jurkiewicz E, Perek D, Kotulska K. Effective everolimus treatment of inoperable, life-threatening subependymal giant cell astrocytoma and intractable epilepsy in a patient with tuberous sclerosis complex. Eur J Paediatr Neurol. 2012;16:83-5.

29. de Vries PJ, Hunt A, Bolton PF. The psychopathologies of children and adolescents with tuberous sclerosis complex (TSC): a postal survey of UK families. Eur Child Adolesc Psychiatry. 2007;16:16-24.

30. Prather P, de Vries PJ. Behavioral and cognitive aspects of tuberous sclerosis complex. J Child Neurol. 2004;19:666-74.

31. Leclezio L, de Vries PJ. Advances in the treatment of tuberous sclerosis complex. Curr Opin Psychiatry. 2015:28:113-20.

32. Leclezio L, Jansen A, Whittemore VH, de Vries PJ. Pilot validation of the tuberous sclerosis-associated neuropsychiatric disorders (TAND) checklist. Pediatr Neurol. 2015;52:16-24.
33. Dixon BP, Hulbert JC, Bissler JJ. Tuberous sclerosis complex renal disease Nephron Exp Nephrol. 2011;118:e15-20.

34. Kessler OJ, Gillon G, Neuman M, Engelstein D, Winkler H, Baniel J. Management of renal angiomyolipoma: analysis of 15 cases. Eur Urol. 1998:33:572-5.

35. Kingswood JC DD, Paola N, Lara L, Elizabeth G, Matthew M. Real-world assessment of renal involvement in tuberous sclerosis complex (TSC) patients in the United Kingdom (UK). Stokholm: EAU; 2014.

36. Rakowski SK, Winterkorn EB, Paul E, Steele DJ, Halpern EF, Thiele EA. Renal manifestations of tuberous sclerosis complex: incidence, prognosis, and predictive factors. Kidney Int. 2006;70:1777-82.

37. Mouded IM, Tolia BM, Bernie JE, Newman HR. Symptomatic renal angiomyolipoma: report of 8 cases, 2 with spontaneous rupture. J Urol. 1978;119:684-8.

38. Shepherd CW, Gomez MR, Lie JT, Crowson CS. Causes of death in patients with tuberous sclerosis. Mayo Clin Proc. 1991;66:792-6.

39. Cudzilo CJ, Szczesniak RD, Brody AS, Rattan MS, Krueger DA, Bissler J J, Franz DN, McCormack FX, Young LR. Lymphangioleiomyomatosis screening in women with tuberous sclerosis. Chest. 2013;144:578-85.

40. Jozwiak S, Kotulska K, Kasprzyk-Obara J, Domanska-Pakiela D, TomynDrabik M, Roberts P, Kwiatkowski D. Clinical and genotype studies of cardiac tumors in 154 patients with tuberous sclerosis complex. Pediatrics. 2006:118:e1146-51.

41. Curatolo P, Moavero R, de Vries PJ. Neurological and neuropsychiatric aspects of tuberous sclerosis complex. Lancet Neurol. 2015;14:733-45.

42. Jozwiak S, Kotulska K, Domanska-Pakiela D, Lojszczyk B, Syczewska M, Chmielewski D, Dunin-Wasowicz D, Kmiec T, Szymkiewicz-Dangel J, Kornacka M, et al. Antiepileptic treatment before the onset of seizures reduces epilepsy severity and risk of mental retardation in infants with tuberous sclerosis complex. Eur J Paediatr Neurol. 2011;15:424-31.

\section{Submit your next manuscript to BioMed Central and we will help you at every step:}

- We accept pre-submission inquiries

- Our selector tool helps you to find the most relevant journal

- We provide round the clock customer support

- Convenient online submission

- Thorough peer review

- Inclusion in PubMed and all major indexing services

- Maximum visibility for your research

Submit your manuscript at www biomedcentral.com/submit
C BioMed Central 